\title{
AUTONOMY ORIENTATION IN ESTONIAN AND SWEDISH FAMILY INTERACTIONS
}

\author{
Tiia Tulviste and Boel De Geer ${ }^{1}$
}

\begin{abstract}
This paper compares the tendency to express autonomy in 20 Estonian, 20 Swedish, and 20 Swedish Estonian middle-class families with preadolescent children during videotaped family mealtimes. The results indicate that compared to the Swedish participants, participants from both Estonian samples expressed autonomy less frequently. Being talkative does not always mean expressing more autonomy. The Swedish preadolescents who were the most talkative and whose mothers were talking less, were more likely to express their personal needs, opinions and preferences.

Possible reasons of cultural variability in autonomy orientation are discussed.
\end{abstract}

Keywords: Autonomy; Family interaction; Socialization; Cross-cultural comparison.

\section{Introduction}

Theories of development suggest that the development of autonomy is one of the most important developmental tasks during adolescence. There have been a lot of theoretical discussions about the meaning of autonomy (see Ryan \& Deci 2006). Recent theoretical argumentation agrees that autonomy is a multifaceted construct (Collins, Gleason \& Sesma 1997; Forman 2007; Kagitçibaşi 2005), and that the traditional view of autonomy as something opposite to dependence, control or help is too simplistic to adequately explain developmental and cultural differences in autonomy (Kagitçibaşi 2005; Ryan \& Lynch 1989). For instance, according to the socio-cultural theory, external control is a source of self-control (Vygotsky 1987; Wertsch 1979). Attachment research has demonstrated that relationship closeness promotes competence development (Matas, Arend \& Stroufe 1978), which, in turn is a contributor to autonomy development.

In research with adolescents, autonomy has most frequently been regarded as decision making or as expressing independent thoughts, desires and experiences. These studies have found that autonomy development depends on how much parents encourage their children to make their own choices, and to express themselves (see Smetana, Crean \& Campione-Barr 2005). For the most part, these studies have relied on adolescents' reports rather than observations of everyday family interactions.

1 Research for this article was supported by a grant from the Baltic Sea Foundation in Sweden (No. 3000903), by a grant from the Estonian Research Competency Council (grant No. SF0180025s08), and by a grant from the Estonian Science Foundation (No. 6511). The authors of this study would like to thank Luule Mizera for helping to gather Estonian data. 
Furthermore, increasing attention has been paid to the question whether autonomy development constitutes a universally expected outcome (Shweder, Goodnow, Hatano, LeVine, Markus \& Miller 1998). Greenfield, Keller, Fuligni and Maynard (2003) identified two different cultural pathways of development: socialization towards independence with an emphasis on individualistic values related to self-achievement, self-actualization, self-expression, and autonomy; and socialization towards interdependence which places importance on group membership, interdependence, and conformity. Autonomy has been shown to be a desired developmental outcome in the families from Western industrialized cultures (e.g. U.S. American, German or Swedish families) where the cultural ideal is independence (Raeff, Greenfield \& Quiroz 2000). For instance, Feldman and Rosenthal (1991) explained the finding that the youth in Hong Kong had later behavioral autonomy than their counterparts in Australia and the US, by putting less emphasis on individualism. Less is known about the likelihood and extent of cultural differences in socialization in various Western countries regarding the promotion of children's autonomy (how much parents encourage their children to make their own choices, to express themselves, to play independently etc.). Based on her studies in Turkey, Kagitçibaşi (1996, 2005) proposed the existence of a third cultural model of development - the model of autonomous relatedness, when the socialization goals focus on independence and autonomy as well as on the integration into the family.

To the extent that individual autonomy varies as an ideal developmental outcome among cultures, mother-child interactions may also differ in respect of how much autonomy is expressed, promoted and supported during family conversations. Few comparative studies have been made to address the question. In a comparative study of German and American mother-child interaction, Budwig (2000) found German toddlers to stress their self in terms of agency less than the Americans. In comparative studies about Japanese and American mother-child interaction, U.S. mothers had more conversations that emphasized individual experience, whereas mothers did not differ in respect of encouraging preschoolers' autonomy expression (Dennis, Cole, Zahn-Waxler \& Mizuta 2002; Dennis, Talih, Cole, Zahn-Waxler \& Mixuta 2007; Wang, \& Leichtman 2000). None of these comparative studies have been made in families with adolescent children.

\section{Talkativeness and autonomy}

Talking is closely connected with the expression of personal views and opinions (Bellah, Madsen, Sullivan, Swidler \& Tipton 1986; Kim 2002; Kim \& Markus 2002). The value placed on talkativeness in autonomy development is related to the suggestion that reticence prevents children from being active participants in exchanging ideas with other people and that they are verbalizing their personal thoughts and opinions less frequently than verbally more outgoing children. This research has usually been conducted in Anglo-European contexts, in the United States and Great Britain, and has examined talkativeness as the means through which people express their ideas and points of views in a specific context (e.g. classrooms).

At the same time it is known that talkativeness carries a psychological "meaning" that varies across cultures (see Kim \& Markus 2002). It is suggested that people in some societies or even in some ethnic groups in the U.S. (e.g., the East Asian Americans) generally talk less because they have different cultural practices and 
meanings of talking or not talking than the talkative European Americans (Kim 2002; Kim \& Markus 2002). Comparative research on family interaction has documented a rather wide cultural variability in respect to how much mothers talk with their children, and how much talk they expect from their children (Bornstein, Tal \& Tamis-LeMonda 1991; Schieffelin \& Ochs 1986). It is possible that in those cultures which do not value talkativeness and personal autonomy as highly as the U. S. culture, talkativeness is not as closely related to individual autonomy expression.

There have not been any studies that have tried to find out the connection between the amount of talk and the extent of expressing one's ideas and points of views. The potential influence of cultural meanings and practices of talking as well as of individual autonomy on family socialization has usually been overlooked.

\subsection{The current study}

The first objective of the current study is to determine whether expression of autonomy during everyday family conversations varies by culture and country of residence. With this aim, we compare the autonomous orientation reflected in the frequency of expressing personal needs, preferences, and avoidances, as well as personal evaluations and opinions, during real-life family mealtime conversations in Estonian families with preadolescents living in Estonia with those of Swedish-Estonian and Swedish families living in Sweden.

On one hand, Estonians and Swedes are relatively similar to each other in many respects. According to widespread stereotypes, both countries belong to "the silent Scandinavian and North European region", where people have been characterized as talking little and only when it is absolutely necessary, sharing the proverb "silence is golden". Furthermore, Estonians and Swedes are relatively similar in the dimensions of individualism and power distance (Hofstede 2001), low population density, the Nordic mentality, and the prevalently Protestant morale. On the other hand, the two countries differ in their historical past and the level of the economic level. While Sweden is a stable Nordic country, Estonia was incorporated into the authoritarian society of the Soviet Union for fifty years. Since 1991, rapid political, economic and cultural changes have occurred in Estonia, which may have had an impact on the socialization values and practices, including autonomy socialization. To date, there are still big differences between the two countries in their economic level: GDP per capita in 2004 (Eurostat Press Office, 2005) expressed in terms of the EU25 average was 50 in Estonia and 116 in Sweden.

According to literature, Sweden is a country where autonomy is a desired developmental outcome (see above). Less is known about the tendency to express and promote autonomy in the socialization of Estonian children. Previous comparative research on family socialization also shows that Swedish families are more egalitarian and less parent-dominated than in many other countries. For example, a comparative study of parental values (see Dahlberg 1992) described Swedish mothers as less strict in their childrearing practices than mothers from 15 other European countries. Estonian mothers, in contrast, appear to put considerably more effort into controlling their teenagers' behavior (Tulviste 2000; Tulviste, Mizera, De Geer \& Tryggvason 2003a), and Estonian children's contribution to family discourse has been found to be smaller than that of Swedish and Estonian teens in Sweden. The directive conversational style 
preferred by Estonian middle-class mothers distinguishes them not only from the U.S. culture (Tulviste 2000), but also from the mothers residing in neighboring countries (in Finland and Sweden), including the Estonian-speaking mothers who live in Sweden (Tulviste, Mizera \& De Geer 2003a). The degree to which the high directiveness of Estonian mothers influences the development of autonomy in children, is an intriguing question. It is generally believed that external control and regulation of toddlers' behavior is valuable as a source for self-regulation and self-control (Kochanska, Coy \& Murray 2001). However, the same strategy may not be the best for autonomy development of older children, especially adolescents. Moreover, offering choices to children has seen as a mechanism of autonomy socialization (see above). Junefelt and Tulviste (1999) found that the number of choices offered to Estonian 2-year-olds children at family meals was significantly smaller than in Swedish and European American families. The findings from a comparative study of parental goals involving Estonian, Finnish and Swedish mothers of 4- to 6-year-old children (Tulviste et al. 2007) provide additional evidence that the Swedish mothers tend to stress individualistic values and attitudes - the characteristics connected with selfmaximization as well as self-confidence and children's happiness. Estonian mothers, in turn, have a combination of individualistic values and attitudes as well as those related to socialization towards interdependence (Tulviste et al. 2007).

The second objective of the study is to address the question whether talkativeness can predict to which extent autonomy is expressed in everyday interactions in families with preadolescent children. Despite belonging to the same stereotypically silent region, both teenagers and their mothers in Estonia appeared to be significantly less talkative than the Swedes. As to the Estonian families who live in Sweden, the mothers were talking as little as Estonian mothers in the country of origin, whereas the teens as much as their peers in Sweden (Tulviste, Mizera, De Geer \& Tryggvason 2003b). The Swedish monocultural mothers, in turn, were as talkative as the European American mothers reported in other studies. Big cultural differences found in previous studies in talkativeness allow us to address the associations between talkativeness and autonomy expression.

Based on the previous findings of family socialization in Estonia and Sweden, we predicted that compared to the preadolescents living in Sweden (both Estonian and Swedish Estonian preadolescents), preadolescents in Estonia would express autonomy less frequently. We also expected that as talkativeness carries culturally varying meanings, it does not predict the extent to how much personal autonomy is expressed during family conversation.

\section{Method}

\subsection{Subjects}

The main targets of the study were preadolescents and their mothers ( 31 to 52 years old, $\underline{\mathrm{M}}=39.10$ ). The mean age of the Estonian preadolescents living in Estonia (Est) was $\underline{\mathrm{M}}$ $=10.80(\underline{\mathrm{SD}}=0.95)$, the Estonian preadolescents living in Sweden (EstSwe) $\underline{\mathrm{M}}=11.75$ $(\underline{\mathrm{SD}}=1.02)$, and the Swedish preadolescents $(\mathrm{Swe}) \underline{\mathrm{M}}=10.90(\underline{\mathrm{SD}}=1.12)$ years. The preadolescent's gender distribution was the following: 8 boys and 12 girls in Est, 10 
boys and 10 girls in SweEst, and 10 boys and 10 girls in Swe families. The preadolescents' gender did not have a significant effect in the later analyses.

Participants were identified through elementary schools, including the Estonian School in Stockholm. Letters briefly describing the study were sent to the preadolescents' families, asking them to indicate their willingness to participate. The data of the Swedish families were collected in Stockholm, the Swedish-Estonian data in Stockholm and Uppsala. Sweden is increasingly characterized by ethnic diversity. In the present study, families from two ethnic groups, from the majority group - the Swedes and from one minority group - the Swedish-Estonians - participated. Swedish-Estonian minority group in Sweden is small: slightly more than 10000 Estonians. In Estonia, the data were collected in Tallinn and Tartu, and only the majority group - the Estonians participated in the study.

\subsection{Procedure}

Video recordings were made during family mealtimes in the homes of the participants. To reduce the observer effect, the researcher visited the participants' homes before the observation session and interacted with all family members. The participants were asked to behave as "normally" as possible, and to ignore the fact that they were being recorded. The participants were told that the mother and the preadolescent must be present, all other family members were encouraged to participate for the meal to be as "ordinary" as possible. Because of that, the number of family members participating at meals varied considerably both within and across samples, $\underline{M}=3.15(\mathrm{SD}=1.18)$ in Est, $\underline{\mathrm{M}}=3.45(\mathrm{SD}=1.05)$ in SweEst, $\underline{\mathrm{M}}=4.15(\mathrm{SD}=1.04)$ in Swe families. The whole mealtime was recorded. The researcher interacted minimally with the participants once the videotaping began. In Est families the mean duration of a meal was $15.48 \mathrm{~min}$, in EstSwe families $21.18 \mathrm{~min}$, and in Swe families $20.38 \mathrm{~min}$. All video recordings were transcribed using the CHAT transcription system (MacWhinney, 1991). The autonomy expression analyses were performed only for the mothers and preadolescents in all families.

\subsection{Measures}

Autonomy expression. The transcripts of family interactions were analyzed for the manifestations of autonomy orientation in expressing independent thoughts, desires, preferences, and experiences. We focused exclusively on the speech measures. We coded only when mothers or adolescents spoke in ways that expressed autonomy (discussing or asking questions about individual experiences, like individual needs, desires, and preferences etc.), but not when answering to questions. The autonomy variable was similar to that used by Wang and Leichtman (2000) for analyzing children's narratives in respect of their tendency to express autonomy.

The composite variable indexes mothers and adolescents' tendency to express autonomy, and consists of three components: 
1. Reference to personal needs, desires, and preferences. The following excerpt (1) recorded between an Estonian monocultural mother and her son illustrates these few cases:

(1)

Mother:mind huvitab eelkõige just see + /. 'I'm most interested in the'

Child: $+<$ see on kell üheksa. 'it's on at 9 o'clock'.'

Mother:viieminutiline lõik.

'a five minute clip.' (from an one-hour program starting at 9 o'clock)

Excerpt (2) is from a Swedish family where the father and his 12 year old daughter are discussing going to a competition where her older brother is taking part.

(2)

\section{Child: på fredag vill jag följa med Mattias på tävlingen}

'on Friday I want to come with Mattias to the competition.'

Father: då får du vara med och heja i så fall.

'in that case you will have to cheer.'

Child: va?

'what?'

Father: du får vara med och heja på lite grann.

'you will have to cheer a little.'

så skärper dom sej på tävlingen.

'it makes them sharpen up during competition.'

2. Reference to personal dislikes and avoidance; for example, see on see kõige halvem asi 'that's the worst thing'; kuule see pole normaalne toit 'listen, it isn't normal food (at school); det e ju bra för jag hatar ju fysik 'that's good because I hate physics.'

3. Expression of personal evaluations, judgments, and opinions regarding other people, objects, or events; for example, minu arvates on see rumal 'I think that is stupid', kolla, precis så där ser alla dom där på Åsö ut, förstår du att hag inte vill gå i den skolan! 'look, that's how all those at Åsö [high school] look like, do you now understand that I won't go to that school!'

The autonomy expression variables were identified and coded by two independent judges. Values for Cohen's kappa calculated ranged from 0.88 to 0.94 . Disagreements were resolved through discussion.

\section{Results}

Table 1 presents the means of the composite variable of autonomy expression per meal and talkativeness of preadolescents and mothers by Culture. 


\subsection{Autonomy expression}

A two-way MANOVA for the composite variable of autonomy expression of preadolescents and mothers showed a main effect of Culture (Est vs. SweEst vs. Swe), Wilks Lambda $\underline{\mathrm{F}}(4,104)=5.62, \underline{\mathrm{p}}<.001$, but no effect of Preadolescent gender and no Culture and Preadolescent gender interaction.

A two-way ANOVA for the composite variable of autonomy expression of preadolescents showed a main effect of Culture, $\underline{F}(2,53)=10.26, \underline{p}<.001$, and a main effect of Preadolescent gender, $\underline{F}(1,53)=4.57, \underline{p}<.05$. Swedish monocultural girls expressed autonomy more frequently $(\underline{M}=7.1)$ than girls and boys from both Estonian samples. The Swedish boys $(\underline{M}=4.3)$ expressed autonomy more than Estonian and Swedish Estonian boys. Follow-up one-way ANOVAs for component variables showed that Culture has an impact on the frequency of expressing personal needs, $\underline{F}(2,56)=$ $5.54, \underline{p}<.01$, and on the expression of personal evaluations, $\underline{F}(2,56)=14.19, \underline{p}<.0001$, as the Swedish monocultural preadolescents expressed them more. One-way ANOVAs revealed a main effect of Preadolescent gender on the expression of personal needs $\underline{F}(1$, $57)=4.15, \underline{p}<.05$, due to the fact that girls expressed their needs verbally more than boys did.

A two-way ANOVA for the composite variable of autonomy expression of mothers showed no effect of Culture, no effect of Preadolescent gender and no Culture and Preadolescent gender interaction. As expected, mothers from different samples did not differ in their tendency to express their autonomy by talking about their personal opinions, needs, likes and dislikes (see Table 1).

Table 1 Means per Meal of the Composite Variable of Autonomy Expression and Talkativeness of Adolescents and Mothers by Culture

\begin{tabular}{|c|c|c|c|c|}
\hline & \multicolumn{4}{|c|}{ Culture } \\
\hline & Est & SweEst & Swe & Fisher LSD Test \\
\hline \multicolumn{5}{|l|}{ Autonomy expression } \\
\hline Adolescent & 1.25 & 2.37 & 5.70 & Swe $>$ Est,SweEst \\
\hline Mother & 1.30 & 2.37 & 1.40 & $\mathrm{~ns}$ \\
\hline \multicolumn{5}{|l|}{ Talkativeness } \\
\hline Adolescent & 3.81 & 4.24 & 6.11 & Swe $>$ Est,SweEst \\
\hline Mother & 7.19 & 6.95 & 10.01 & Swe $>$ Est,SweEst \\
\hline
\end{tabular}

Note. The samples are marked as follows: Est $=$ Estonians; SweEst $=$ Swedish Estonians; Swe $=$ Swedish.

T-tests showed that in the Swedish monocultural sample, preadolescents expressed autonomy significantly more than their mothers, $\underline{\mathrm{t}}(19)=4.17, \underline{\mathrm{p}}<.05)$, whereas in Estonian and Swedish Estonian samples there was no significant difference between mothers and preadolescents in the frequency of expressing autonomy (see Table 1).

To control for the possibility that the results of our analyses are artifacts of the number of family members participating at meals, Pearson's correlation analyses were conducted. The analyses revealed no significant $($ at $p<.05)$ correlations between the 
number of participants and the number of autonomy expressions of mothers and teenagers.

\subsection{Talkativeness}

The two-way ANOVA for preadolescents' talkativeness (words per minute) showed a main effect of culture, $\mathrm{F}(2,54)=8.08, \mathrm{p}<.001$, and no effect of Preadolescent gender, and no Culture and Preadolescent gender interaction. Swedish preadolescents talked significantly more than others (see Table 1).

There was an effect of Culture on mothers' talkativeness, $\underline{F}(1,54)=9.89$, p < .001 , but no significant Preadolescent gender effect and no Culture and Preadolescent gender interaction. The Swedish monocultural mothers talked significantly more than the mothers from other samples (see Table 1). In all samples, mothers were significantly more talkative than their preadolescents.

\subsection{Talkativeness and autonomy expression}

Preadolescents' talkativeness and autonomy expression were correlated positively and significantly in the Estonian and the Swedish (respectively, $\underline{r}=.59$, and $\underline{r}=.47$ ), but not in the Swedish Estonian sample. Mothers' talkativeness was not related to their composite score of autonomy expression.

A multiple regression analysis revealed that $44 \%$ of the variance of the autonomy expression by preadolescents is predicted by the talkativeness and Culture, $\mathrm{F}$ $(4,54)=12.30, \mathrm{p}<.00001$. As expected, preadolescents' talkativeness $(\beta=.52)$ was the strongest predictor, but also Culture $(\beta=.40)$ and mothers' talkativeness $(\beta=-.34)$ made strong contributions to how much autonomy preadolescents expressed. The Swedish preadolescents who were the most talkative and whose mothers were talking less, were more likely to express their personal needs, opinions and preferences.

\section{Discussion}

The first objective of the study was to compare the manifestations of autonomy orientation in expressing personal needs, preferences, and avoidances, as well as personal evaluations and opinions during real-life family mealtime conversations in Estonian, Swedish Estonian and Swedish families with preadolescent children. Taking into account the more liberal and child-centered parenting styles in Sweden as compared to other countries, including Estonia, observed in previous family socialization research, we expected families in Sweden to have been promoting autonomy in the socialization of children more, and as a result preadolescents living in Sweden (both Estonian and Swedish) to express autonomy more frequently in family conversations than preadolescents in Estonia.

Results indicated that only those preadolescents in Sweden who where from Swedish monocultural families expressed their personal opinions more frequently than their peers in Estonia. In the following example (3) a Swedish family discusses previous 
plans to buy a pair of telescopes as a Christmas gift. In three places the girl expresses her wishes and opinions.

(3) Talking about telescopes. The child is a girl of 10 years.

Father: det skulle vi köpa till dej förra julen. 'we were going to buy you that last Christmas'

Mother:ja just det 'yes, that's right.'

Father: det kommer jag ihåg 'I remember that.' fast sen var det nåt annat du skulle ha 'but then there was something else you needed.'

Mother:jag tror inte dom var så bra heller 'I don't think they were that good either.'

Father: näe

'no.'

dom e jättejättedyra.

'they are ever so expensive.'

Child: det önskar jag mej i födelsedagspresent 'that's what I want for birthday present.' det är nog jättekul tror ja. 'it is great fun I think.' men det är lite konstigt för/ äääh... 'but maybe a little strange because/eeeh' det stod ju i/ja kanske missuppfatta det men nästan alla stjärnor... 'it was written in/maybe I misunderstood it but almost all stars...' det är som solar. 'they are like suns.'

Father: $\mathrm{mm}$.

precis 'precisely'

Child: jag tycker det är jättekonstigt. 'I think that is so strange.'

The Swedish girls showed more autonomy than any other preadolescents, and Swedish boys expressed more autonomy than Estonian and Swedish Estonian boys. The preadolescents from Estonian families living in Sweden were similar to the Estonian preadolescents residing in their country of origin in expressing little autonomy.

No cultural differences emerged in maternal talk in respect to how frequently autonomy was expressed. The qualitative cultural difference observed was the Estonian and Swedish Estonian mothers' tendency to talk frequently about what their preadolescents like, dislike and think than about what they themselves do, as illustrated by Excerpt (4) featuring Swedish-Estonian mother-boy discourse. Instances where the mother talks instead of her grown-up child were not typical of Swedish monocultural mothers' talk.

Mother: et huvitav jah suusatada te keegi eriti teie klassist vist ei tunne huvi jah. 
Child:

'interesting yeah that skiing nobody in your class really is interested in.'

jah.

'yes.'

Mother: paistab jah et ei ole te kovad suusatajad.

'yeah, looks that you aren't much of skiers.'

enne meeldib teile ujuda.

'you'd rather swim.'

Child: jah.

'yes.'

It is likely that Swedish Estonian mothers talked about personal views, needs, preferences, and avoidances of their teenagers because they expected in this way to elicit the teenagers' autonomy talk.

The second objective of the study was to address the possible relationship between the amount of talk and the extent of expressing ideas and points of views, as well as personal needs, preferences, and avoidances. According to our data, preadolescents' talkativeness correlated with the tendency to express autonomy in Estonian and Swedish samples, but not in the Estonian Swedish sample. No correlation has been observed between mothers' talkativeness and their autonomy expression. Although both Swedish monocultural teens and their mothers were more talkative than Estonians and Swedish Estonians, no cultural differences were found in maternal talk in respect to autonomy expression. At the same time, Swedish girls differed from all other preadolescents, and Swedish boys from all other boys due to their greater autonomy expression.

Furthermore, mothers produced significantly more talk than preadolescents in all families. In Estonian and Swedish Estonian families mothers expressed autonomy to the same extent as preadolescents, whereas in Swedish families preadolescents expressed it significantly more than their mothers. Thus, our study showed the resemblance of Estonian preadolescents to their mothers in terms of autonomy expression both in Estonia and Sweden. At the same time, in Swedish monocultural families preadolescents were significantly more autonomy orientated than their mothers. In addition, the study provided evidence that being talkative, as far as family interactions are concerned, does not always mean having greater autonomy orientation. The Swedish preadolescents who were the most talkative and whose mothers were not talking a lot, were more likely to express their independent thoughts, desires and preferences.

It should be mentioned here that the current study investigated how much autonomy teens express during family conversations. It is clear that the observed cultural differences in talkativeness as well as in autonomy expression have resulted not only from cultural differences in family socialization. Socialization in peer groups and at school plays an important role especially during the adolescence years. It is possible that in other interaction contexts, for example, in peer interaction, Estonian and Swedish Estonian preadolescents would express autonomy more frequently.

However, the results of a comparative study about socialization values show that Estonian mothers value individualistic values as highly and conformity values more highly than mothers from Sweden and Finland, combining the transition toward individualistic values with an emphasis on values typical of socialization towards interdependence (Tulviste et al. 2007). The results of the present study were similar to previous observational studies about everyday family conversation showing that the pattern of family discourse in Estonia is traditional: Estonian mothers do not support 
children's autonomy to the same extent mothers from Swedish families in Sweden do. Further studies should answer the question whether socialization of children in Estonia is shifting from one cultural pathway of development (towards interdependence) to another (towards independence) or Estonia is a culture with autonomous relatedness proposed by Kagitçibaşi (2005).

It would be interesting to compare the preadolescents' tendency to express autonomy also in some other contexts. As said before, previous research concerning talkativeness and autonomy expression has been done mostly in classroom context and has involved high school and college students (Kim \& Markus 2002). It is known that willingness to communicate depends largely on the context of interaction and the partner of interaction (McCroskey, Burroughs, Daun \& Richmond 1990). Communication apprehension is stronger in public speaking, such as making a presentation before the class, and weaker in dyads with family members or friends. One might expect even bigger cultural differences in talkativeness and autonomy expression in school context than those observed in the current study.

Although the present study compared countries similar to each other despite their different historical past and economic situation, the observed results support the suggestion that the significance of autonomy socialization at home is moderated by cultural context. According to literature, Swedish culture is a typically autonomysupporting culture (see above). Despite that, only Swedish monocultural teenagers, but not Swedish Estonian teenagers expressed autonomy more frequently than teenagers from the Estonian families living in Estonia, and there was no cultural differences among mothers in their autonomy talk.

\section{References}

Bellah, R.N., R. Madsen, W.M. Sullivan, A. Swidler, and S.M. Tipton (1986) Habits of the heart. New York: Harper \& Row.

Bornstein, M.H., J. Tal, and C.S. Tamis-Le Monda (1991) Parenting in cross-cultural perspective: The United States, France and Japan. In M.H. Bornstein (ed.), Cultural approaches to parenting. Hillsdale, NJ: Lawrence Erlbaum, pp 69-90.

Budwig, N. (2000) Language and the construction of self. In N. Budwig, I.Č. Uzgiris, and J.V. Werstsch (eds.), Communication: An arena of development. Stamford, C: Ablex, pp 195-214.

Collins, W.A., T. Gleason, and A. Sesma (1997) Internalization, autonomy, and relationships: Development during adolescence. In J.E. Grusec \& L. Kuczynski (eds.), Parenting and children's internalization of values. A handbook of contemporary theory. New York: Wiley, pp. 78-99.

Dahlberg, G. (1992) The parent-child relationship and socialization in the context of modern childhood: The case of Sweden. In J.L. Roopnarine and D.B. Carter (eds.), Parent-child socialization in diverse cultures. Norwood, NJ: Ablex, pp. 121-137.

Dennis, T.A., P.M. Cole, C. Zahn-Waxler, and I. Mizuta (2002) Self in context: Autonomy and relatedness in Japanese and U.S. mother-preschooler dyads. Child Development 73: 1803-1817.

Dennis, T.A., M. Talih, P.M. Cole, C. Zahn-Waxler, and I. Mizuta (2007) The socialization of autonomy and relatedness. Sequential verbal exchanges in Japanese and U.S. mother-preschooler dyads. Journal of Cross-Cultural Psychology 38: 729-749. 
Feldman, S.S., and D.A. Rosenthal (1991) Age expectations of behavioral autonomy in Hong Kong, Australian and American youth: The influence of family variables and adolescents' values. International Journal of Psychology 26: 1-23.

Forman, D.R. (2007) Autonomy, compliance, and internalization. In C.A. Brownell \& C.B. Kopp (eds.), Socioemotional development in the toddler years. Transitions and Transformations. New York, London: Guilford Press.

GDP per capita in 2004. (75/2005 - 3 June 2005). Retrieved May 5, 2005, from http://epp.eurostat.cec.eu.int/pls/portal/docs/PAGE/PGP_PRD_CAT_PREREL/PGE_CAT_P EREL_YEAR_2005/PGE_CAT_PREREL_YEAR_2005_MONTH_06/2-03062005-EN-BP.PDF

Greenfield, P.M., H. Keller, A. Fuligni, and A. Maynard (2003) Cultural development through universal developmental tasks. Annual Review of Psychology 54: 1-23.

Hofstede, G. (2001) Culture's consequences: Comparing values, behaviors, institutions, and organizations across nations. Thousand Oaks, CA: Sage.

Junefelt, K., and T. Tulviste (1999) A question of choice. In Psycholinguistics on the threshold of the year 2000. Proceedings of the 5th International Congress of the International Society of Applied Psycholinguistics. 25-27 June 1997, Porto, Portugal, 317-321.

Kagitçibaşi, Ç. (1996) Family and human development across cultures. Mahwah, NJ: Lawrence Erlbaum.

Kagitçibaşi Psycholinguistics on the threshold of the year, Ç. (2005) Autonomy and relatedness in cultural context. Implications for self and family. Journal of Cross-Cultural Psychology 36: 403-422.

Kim, H.S. (2002) Speech and silence: A cultural analysis of the effect of talking on psychology. Dissertation Abstracts International: Section B: The Sciences and Engineering 62.9-B, April 2002.

Kim, H.S., and H.R. Markus (2002) Freedom of speech and freedom of silence: An analysis of talking as a cultural practice. In R.A. Shweder, M. Minow, \& H.R. Markus (eds.), Engaging cultural differences: The multicultural challenge in liberal democracies. New York: Russell Sage Foundation, pp. 432-452.

Kochanska, G., K.C. Coy, and K.T. Murray (2001) The development of self-regulation in the first four years of life. Child Development 72: 1091-1111.

MacWhinney, B. (1991) The CHILDES project: Tools for analyzing talk. Hillsdale, NJ: LEA.

Markus, H., and S. Kitayama (1991) Culture and the self: Implications for cognition, emotion, and motivation. Psychological Review 98: 224-253.

Matas, L., R.A. Arend, and L.A. Stroufe (1978) Continuity of adaptation in the second year: The relationship between quality of attachment and later competence. Child Development 49: 547-556.

McCroskey, J.C., N.F. Burroughs, Å. Daun,.and V.P. Richmond (1990) Correlates of quietness: Swedish and American perspectives. Communication Quarterly 2: 127-137.

Raeff, C., P.M. Greenfield, and B. Quiroz (2000) Conceptualizing interpersonal relationships in the cultural contexts of individualism and collectivism. In S. Harkness, C. Raeff, \& C.M. Super (eds.), Variability in the social construction of the child: New directions in child and adolescent development. Vol. 87. San Francisco: Jossey-Bass, pp 59-74.

Ryan, R.M., and E.L. Deci (2006) Self-Regulation and the problem of human autonomy: Does psychology need choice, self-determination, and will? Journal of Personality 74: 1557-1595. 
Ryan, R.M., and J.H. Lynch (1989) Emotional autonomy versus detachment. Revisiting the vicissitudes of adolescence and young adulthood. Child Development 60: 340-356.

Schieffelin, B.B., and E. Ochs (eds.) (1986) Language socialization across cultures. Cambridge: Cambridge University Press.

Shweder, R.A., J.J. Goodnow, G. Hatano, R.A. LeVine, H. Markus, and P. Miller (1998) The cultural psychology of development: One mind, many mentalities. In R.M. Lerner (Vol. ed.) \& W. Damon (Series ed.), Handbook of child psychology. Vol. 1: Theoretical models of human development. New York: Wiley, pp. 865-937.

Smetana, J., H. Crean, and N. Campione-Barr (2005) Adolescents' and parents' changing conceptions of parental autority. New Directions for Child and Adolescent Development 108: 31-46.

Tulviste, T. (2000) Socialization at meals: A comparison of American and Estonian mother-adolescent interaction. Journal of Cross-Cultural Psychology 31: 537-556.

Tulviste, T., L. Mizera, B. De Geer, and M.-T. Tryggvason (2003a) A comparison of Estonian, Swedish, and Finnish mothers' controlling attitudes and behavior. International Journal of Psychology 38: 11-18.

Tulviste, T., L. Mizera, B. De Geer, and M.-T. Tryggvason (2003b) A silent Finn, a silent Finno-Ugric, or a silent Nordic? A comparative study of Estonian, Finnish and Swedish mother-adolescent interactions. Applied Psycholinguistics 24 : 249-265.

Tulviste, T., L. Mizera, B. De Geer, and M.-T. Tryggvason (2007) Child-rearing goals of Estonian, Finnish, and Swedish mothers. Scandinavian Journal of Psychology 48.8: 487-

Vygotsky, L.S. (1987) Thought and language. Cambridge, MA: MIT Press.

Wang, Q., and M.D. Leichtman (2000) Same beginnings, different stories: A comparison of American and Chinese children's narratives. Child Development 71: 1329-1346.

Wertsch, J.V. (1979) From social interaction to higher psychological processes: A clarification and application of Vygotsky's theory. Human Development 22: 1-22. 